\title{
Understanding a Hydroformylation Catalyst that Produces Branched Aldehydes from Alkyl Alkenes
}

\author{
Paul Dingwall, José A. Fuentes, Luke Crawford, Alexandra M. Z. Slawin, Michael Bühl*, and Mat- \\ thew L Clarke*
}

School of Chemistry, University of St. Andrews, EaStCHEM, St. Andrews, Fife, KY16 9ST (UK)

\begin{abstract}
This paper reports experimental and computational studies on the mechanism of a rhodium-catalysed hydroformylation that is selective for branched aldehyde products from unbiased alkene substrates. This highly unusual selectivity relies on a phospholane-phosphite ligand prosaically called BOBPHOS. Kinetic studies using in situ high pressure IR (HPIR) and the reaction progress kinetic analysis methodology suggested two steps in the catalytic cycle were involved as turnover determining. Negative order in $\mathrm{CO}$ and positive orders in alkene and $\mathrm{H}_{2}$ were found and the effect of hydrogen and carbon monoxide partial pressures on selectivity were measured. Labelling studies found rhodium hydride addition to the alkene to be largely irreversible. Detailed spectroscopic HPIR and NMR characterization of activated rhodium-hydrido dicarbonyl species were carried out. In the absence of $\mathrm{H}_{2}$, reaction of the rhodium-hydrido dicarbonyl with allylbenzene allowed further detailed spectroscopic characterization of four- and five-coordinate rhodium-acyl species. Under singleturnover conditions the ratios of branched to linear acyl species were preserved in the final ratios of aldehyde products. Theoretical investigations uncovered unexpected stabilizing $\mathrm{CH}-\pi$ interactions between the ligand and substrate which influenced the high branched selectivity by causing potentially low energy pathways to become unproductive. Energy span and degree of TOF control analysis strongly support experimental observations and mechanistic rationale. A threedimensional quadrant model was built to represent the structural origins of regio- and enantioselectivity.
\end{abstract}

\section{INTRODUCTION}

Many millions of tonnes of aldehydes are produced industrially using rhodium catalysed hydroformylation of alkenes. ${ }^{1}$ The majority of these aldehydes are linear regioisomers derived from the hydroformylation of 'alkyl' alkenes. However, there are some branched aldehyde products such as iso-butanal that are isolated at commercial scale from mixtures of regioisomers, and a further larger group of products that could desirably be accessed via branched selective hydroformylation of an alkyl alkene. To increase efficiency in the former reactions and to make the latter reactions a viable strategy requires catalysts that are capable of forming the branched aldehyde from a terminal alkyl alkene with significant regioselectivity. Extensive studies, albeit generally devoted to discovering more linear selective catalysts, show that the linear isomer is preferred in nearly every case when alkyl alkenes take the form $\mathrm{XCH}_{2} \mathrm{CH}=\mathrm{CH}_{2}$ (X can be any carbon chain). ${ }^{2,3}$ There is therefore a strong demand for new branched selective hydroformylation catalysts, for achiral, racemic and enantio-enriched products. Enantioselective hydroformylation is slowly coming of age as a potentially clean, low cost, and atom-efficient method to make chiral aldehydes. Studies on enantioselective hydroformylation generally focus on specific classes of substrate that have an inbuilt propensity to primarily form branched aldehydes. ${ }^{4-10}$ In fact, forming branched aldehydes from alkyl alkenes, even using achiral catalysts is very unusual. ${ }^{11}$ Alongside projects exploiting substrate-controlled regioselectivity, sporadic attempts were made in our laboratories to address the highly desired enantioselective hydroformylation of alkyl alkenes. This led to the serendipitous discovery of a phospholanephosphite that could indeed preferentially deliver the branched aldehyde from alkyl alkenes with high enantioselectivity.12-14We have now uncovered how our system works through the use of in situ kinetic studies, isotopic labelling studies, spectroscopic investigation of catalyst intermediates, along with DFT calculations and report these findings here.

\section{RESULTS AND DISCUSSION}

There are many examples of phosphine-phosphite (and phosphine-phosphoramidate) ligands in the literature, and the development of BINAPHOS ${ }^{15}$ was a particular landmark in hydroformylation research. The phospholane-phosphite ligand system studied here (Scheme 1) was developed to assess what might result if we made a phosphinephosphite that took the "Best bits of Both PHOSphorus" ligands, Kelliphite and Ph-BPE, which were commercially viable catalysts for enantioselective hydroformylation being used by Chirotech/DOW (now Dr Reddys). The unfortunately catchy laboratory acronym of B.O.B.PHOS seems to have caught on, and we will refer to the ligand as BOBPHOS throughout this paper for simplicity.

Some typical examples of Rh/BOBPHOS catalysed branched selective hydroformylation are shown in Scheme 1. For example, hex-1-ene, normally biased towards linear aldehyde formation, gave 3:1 branched selectivity and high 
er. Other examples demonstrate very high reactivity, at low catalyst loadings with styrene and its derivatives, as well as utility in the synthesis of more functionalized products. ${ }^{12-14}$
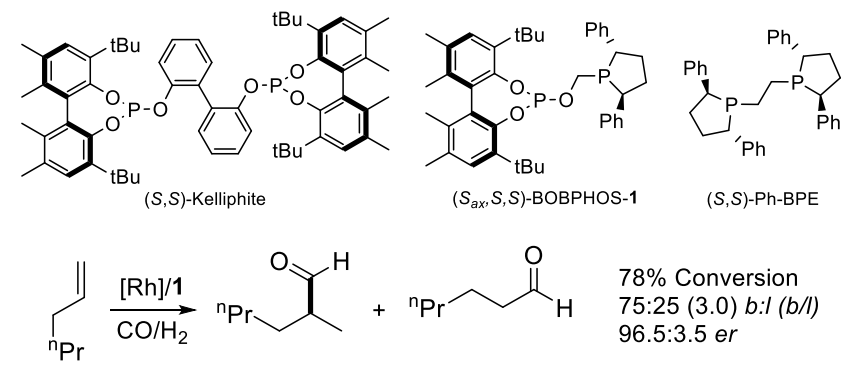

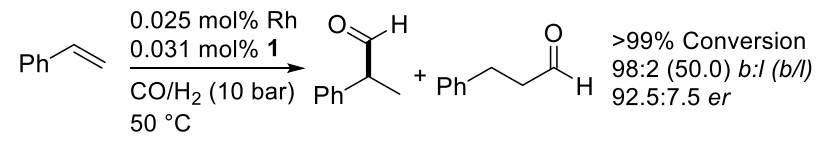

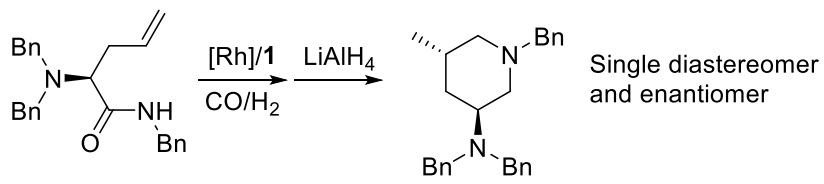

Scheme 1: BOBPHOS parent ligands and selected examples of high branched selectivity.

BOBPHOS is now commercially available ${ }^{16}$ and two significant improvements in the ligand synthesis have been made to satisfy demand for multigram quantities (Scheme 2). Firstly, the use of bromophosphite, over the previously reported iodophosphite ${ }^{12}$ results in an improved yield. Previously we resolved BIPHEN prior to coupling with the enantiopure phospholane moiety. However, we found it is more convenient to utilise racemic BIPHEN and resolve the $\left(S_{a x}, S, S\right)$-BOBPHOS from the $\left(R_{a x}, S, S\right)$-BOBPHOS diastereomer by recrystallisation in excellent purity.

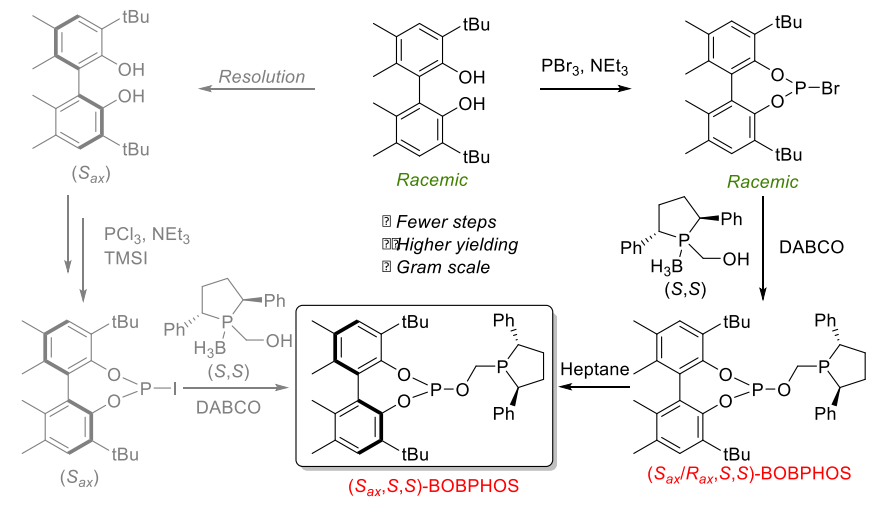

Scheme 2: Improved synthetic route to enantiopure BOBPHOS

Crystal structures of the $\mathrm{Rh}(\mathrm{H})(\mathrm{CO})_{2} \mathrm{~L}$ resting states for hydroformylation are rare, and our attempts at growing crystals from a variety of $\mathrm{Rh}$ complexes of $\left(S_{a x}, S, S\right)$ BOBPHOS were not successful. $\left(S_{a x}, S, S\right)$-BOBPHOS was instead reacted with $\left[\mathrm{PdCl}_{2}(\mathrm{PhCN})_{2}\right]$ to give cis- $\mathrm{PdCl}_{2}\left(S_{a x}, S, S\right)$ BOBPHOS, 2. Single crystals suitable for X-ray crystal structure analysis were grown, with the structure determined by X-ray crystallography. The structure is displayed in Figure 1. If one considers the four quadrant areas of a square planar complex, two can be considered blocked by either the phospholane $\mathrm{Ph}$ ring in the bottom right or one of the tert-butyl groups in the top left. The $\mathrm{Pd}-\mathrm{Cl}$ bond trans to the phosphite is slightly shorter in length at 2.342(3) Å compared to 2.348(3) Å trans to the phosphine. The crystallographic bite angle, $86.13(9)^{\circ}$, is close to the reported bite angle of $85.82(7)^{\circ}$ for $\mathrm{PdCl}_{2}$ (dppe). ${ }^{17}$

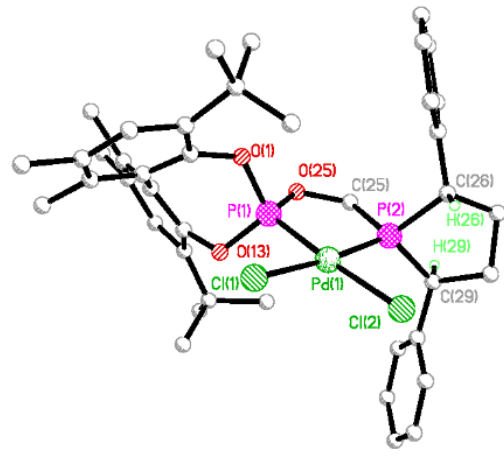

Figure 1: X-ray structure of [ $\mathrm{PdCl}_{2}\left(\mathrm{~S}_{a x}, S, S\right)$-BOBPHOS $] 2$

We envisaged that an in-depth analysis of the branched selective asymmetric hydroformylation of allylbenzene as a model substrate could prove a useful tool in determining the origins of the high selectivities displayed by $\mathrm{Rh} /$ BOBPHOS catalyst.

\section{Kinetic Analysis}

Our original studies for this substrate were carried out at $16{ }^{\circ} \mathrm{C}$ over extended reaction times to give $80 \%$ branched product of 95:5 er. However, similar selectivity was obtained at $40{ }^{\circ} \mathrm{C}$, which was more convenient for a kinetic analysis as well as a synthetic perspective. As expected, $4 \mathrm{~b}$ branched selectivity does fall off at significantly higher temperatures. ${ }^{4 c}$

Our analysis began by probing concentration or partial pressure dependencies of the reaction substrates to determine a global rate equation. In situ HPIR spectroscopy was employed to continuously monitor the reaction progress under synthetically relevant conditions, an important consideration in hydroformylation. Identical reaction rates were observed for reactions catalysed using $\mathrm{Rh}$ :BOBPHOS ratios of either $1: 1.25$ or $1: 2.5$, indicating that no competitive binding between excess BOBPHOS and allylbenzene occurs using synthetically meaningful ligand concentrations. Variation of the stirring speed of the overhead stirrer, from 1200 to $1500 \mathrm{rpm}$, resulted in no change in reaction rate; under these conditions and in the pressure vessel used the reaction is not under mass transfer limitations. ${ }^{18}$

Order in catalyst was determined using a graphical method developed by Burés ${ }^{19}$ (Figure 2a) and was found to be first order (full analysis can be found in Figure S11) ruling out the formation of parasitic dimeric rhodium complexes during catalysis. Further, no bands at $c a .1800 \mathrm{~cm}^{-1}$, characteristic of bridging carbonyl stretches, were observed at any time during catalysis.

It was immediately apparent from the linear reaction profile observed when plotting rate against [Allylbenzene] that the reaction is first order in alkene (Figure $2 \mathrm{~b}$ ). The graphical rate equation methodology of Reaction Progress 

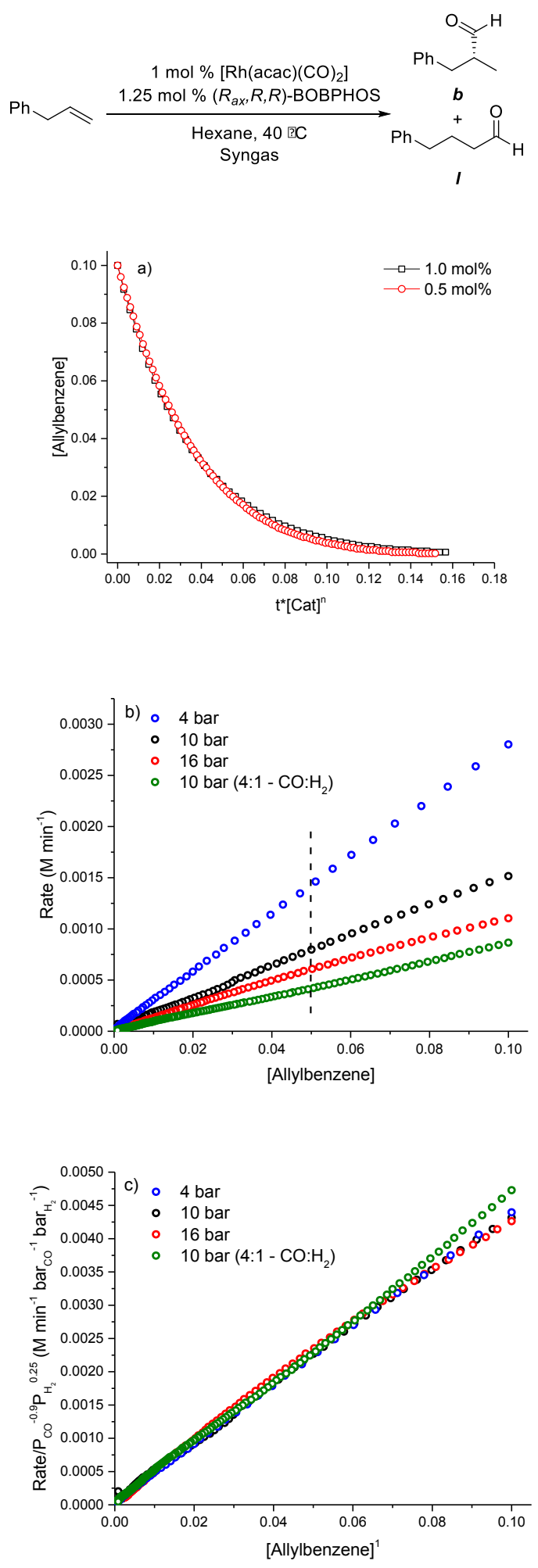

Figure 2: Reaction profiles as monitored by HPIR spectroscopy for the reactions of Table 1: (a) catalyst order as determined by overlay of the two kinetic profiles of reactions performed at 1.0 and $0.5 \mathrm{~mol} \%$ catalyst loadings, 4 bar syngas; (b) reaction rate vs. [Allylbenzene] at different pressures of syngas; (c) reaction rate divided by the partial pressures of $\mathrm{CO}$ and $\mathrm{H}_{2}$ raised to chosen powers determined through achievement of overlay vs [Allylbenzene] to determine substrate orders. Reaction progress is from right to left in (b) and (c). All experiments [Allylbenzene] 0 $=0.1 \mathrm{M} ; \mathrm{L}: \mathrm{Rh}=1.25 ; 40^{\circ} \mathrm{C}$; hexane; conversion $>98 \%$.
Kinetic Analysis (RPKA) ${ }^{20}$ was employed to determine substrate orders with a minimum number of experiments. The different excess protocol of RPKA, which was followed by changing the pressure of syngas for each reaction, relies on the manual manipulation of reaction orders; these are graphically determined as correct when the various reaction profiles 'overlay'. Overlay was achieved (Figure $2 \mathrm{c}$ ) when orders for $\mathrm{P}_{\mathrm{CO}}$ and $\mathrm{P}_{\mathrm{H} 2}$ of -0.90 and 0.25 respectively were chosen (see Figure S12 for full analysis).

These graphically determined orders can be verified via quantitative assessment, requiring a further experiment carried out at a different $\mathrm{CO}: \mathrm{H}_{2}$ ratio, here $4: 1$ (Figure $2 \mathrm{~b}$ and c). Values of -0.92 and 0.28 are found respectively for $\mathrm{P}_{\mathrm{Co}}$ and $\mathrm{P}_{\mathrm{H}_{2}},{ }^{18}$ in good agreement with those determined by graphical analysis, leading to empirical power law Equation 1 to represent the combined linear and branched pathways.

$$
\begin{aligned}
& \text { rate }=k_{\text {obs }} \cdot[\text { Cat }]^{x} \cdot[\text { Alkene }]^{y} \cdot P_{C O}{ }^{m} \cdot P_{\mathrm{H}_{2}}{ }^{n} \\
& \quad=k_{\text {obs }} \cdot[\text { Cat }]^{1} \cdot[\text { Alkene }]^{1} \cdot P_{C O}{ }^{-0.90} \cdot P_{H_{2}}{ }^{0.25}
\end{aligned}
$$

These data, first order in catalyst, first order in alkene, negative order in $\mathrm{CO}$, and positive order in $\mathrm{H}_{2}$, suggest that more than one step in the catalytic cycle (Scheme 3 ) have similar rates and are behaving as turnover determining. More specifically, one or both of the early steps of alkene coordination/hydride transfer likely have similar rates to the product forming hydrogenolysis. If this is so, both the hydrido dicarbonyl 3 and acyl dicarbonyl 9 resting states might be observed as turnover determining intermediates.

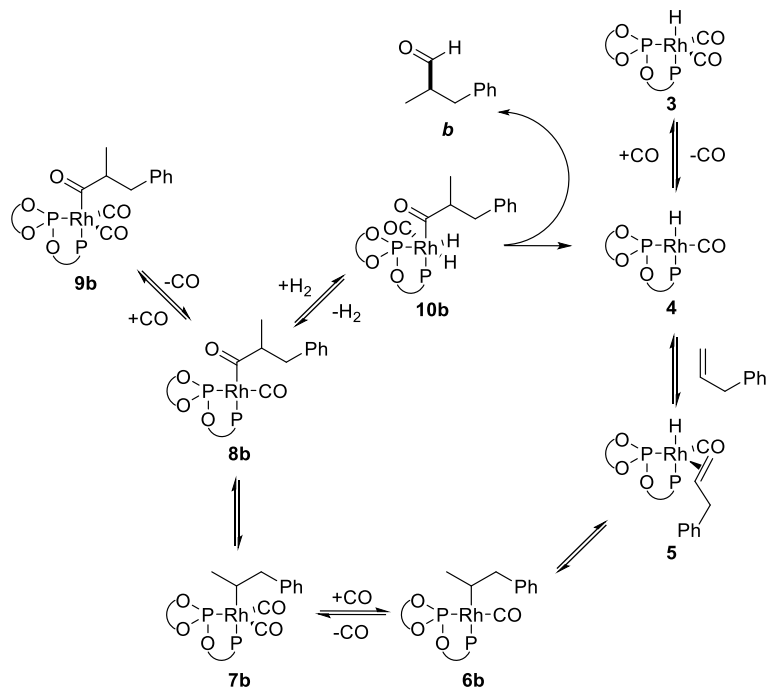

Scheme 3: General mechanism for rhodium catalysed hydroformylation showing branched pathway.

Multiple turnover determining steps operating in a single catalytic cycle have been reported by van der Slot and coworkers on their studies of monodentate phosphorous diamide ligands in the hydroformylation of 1-octene. ${ }^{21}$ However, this behaviour is unusual for bidentate ligands in hydroformylation. For instance, both Rh/BisDiazaphos and $\mathrm{Rh} /(R, S)$-BINAPHOS systems are positive order in alkene, negative order in $\mathrm{CO}$ and zero order in $\mathrm{H}_{2}$ in the hydroformylation of styrene. ${ }^{22}$

The reaction can be run at low loadings of $\mathrm{Rh}, 0.075 \mathrm{~mol} \%$, albeit with a drop in selectivities due to the higher 
Table 1: Total and partial pressures of gases used for experiments in Figure 2 and the resulting selectivities.

\begin{tabular}{|c|c|c|c|c|c|c|c|}
\hline \multirow[b]{2}{*}{ Entry } & \multirow[b]{2}{*}{$\mathrm{CO}: \mathrm{H}_{2}$} & \multicolumn{3}{|c|}{$\begin{array}{c}1 \mathrm{~mol} \%\left[\mathrm{Rh}(\mathrm{acac})(\mathrm{CO})_{2}\right] \\
1.25 \mathrm{~mol} \%\left(R_{\mathrm{ax}}, R, R\right)-\mathrm{BOBPHO}\end{array}$} & \multirow{2}{*}{ 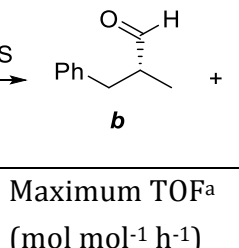 } & I & \\
\hline & & $\begin{array}{l}\mathrm{P}_{\text {Tot }} \\
\text { (bar) }\end{array}$ & $\begin{array}{l}\mathrm{P}_{\mathrm{CO}} \\
\text { (bar) }\end{array}$ & $\begin{array}{l}\mathrm{P}_{\mathrm{H}_{2}} \\
\text { (bar) }\end{array}$ & & $b: l^{b}$ & $e r^{c}$ \\
\hline 1 & $1: 1$ & 4 & 2 & 2 & 168 & $79: 21$ & $93.5: 6.5$ \\
\hline 2 & $1: 1$ & 10 & 5 & 5 & 89 & $80: 20$ & $92.0: 8.0$ \\
\hline 3 & $4: 1$ & 10 & 8 & 2 & 52 & 81:19 & 92.5:7.5 \\
\hline 4 & $1: 1$ & 16 & 8 & 8 & 66 & 81:19 & $93.5: 6.5$ \\
\hline 5 & $1: 1$ & 32 & 16 & 16 & 18 & $82: 18$ & $93.5: 6.5$ \\
\hline $6^{d}$ & $1: 1$ & 4 & 2 & 2 & 978 & $69: 31$ & 88.5:11.5 \\
\hline
\end{tabular}

Allylbenzene $0.1 \mathrm{M}$, all conversions > 98\% as measured by NMR using 1-methylnaphthalene as internal standard, $\left[\mathrm{Rh}(\mathrm{acac})(\mathrm{CO})_{2}\right]$ and BOBPHOS were stirred under pressure of syngas and at temperature until formation of the active species was complete as observed by IR; a)Maximum TOF is rate over mol catalyst; b)determined via NMR spectroscopy; c)measured via HPLC analysis using a chiralcel OD-H column on the corresponding alcohol after reduction by $\mathrm{NaBH}_{4} ; \mathrm{d}^{0.075} \mathrm{~mol} \% \mathrm{Rh} .0 .188 \mathrm{~mol} \%$ BOBPHOS, $60^{\circ} \mathrm{C}$.

temperature, $60{ }^{\circ} \mathrm{C}$, used to achieve high turnover frequency (Table 1, entry 6). Analysis of selectivity data in Table 1 (comparing entries 1,3 , and 5) shows only very small changes in selectivity as pressure of $\mathrm{CO}$ is increased. Comparing entries 3 and 4 shows that regio- and enantioselectivity is essentially independent of the hydrogenpressure (in the normal range of operating pressures). This is consistent with hydrogenolysis playing no role in either the regio- or enantioselectivity determining step in the catalytic cycle.

\section{Spectroscopic Study of Intermediates}

Complexation of BOBPHOS to [Rh(acac)(CO) 2 is essentially instantaneous and under pressure of syngas this complex reacts to form the active rhodium hydrido dicarbonyl complex 3 cleanly as a single species (Scheme 4).

The asymmetric nature of the two observed bands, at 2029 and $1977 \mathrm{~cm}^{-1}, 23$ (Scheme $4 \mathrm{a}$ ) is fully consistent with a single axial-equatorial coordination of the ligand. ${ }^{31} \mathrm{P}\left\{{ }^{1} \mathrm{H}\right\}$ NMR spectroscopy (Scheme $4 \mathrm{~b}$ ) at ambient temperature and pressure under syngas reveals JP-Rh couplings for the phosphite and phospholane of 229 and $104 \mathrm{~Hz}$ respectively; these remain essentially unchanged at low temperature $\left(-71^{\circ} \mathrm{C}\right)$ suggesting one isomer. ${ }^{15 j}$ The magnitudes of these couplings are consistent with the phosphite occupying an equatorial site and the phospholane an axial site in a trigonal bipyramidal geometry. The magnitude of the $\mathrm{J}_{\mathrm{H}-\mathrm{Rh}}$ coupling (Scheme 4 c), $\delta$-8.32 (ddd, JH-Ptrans 116 Hz, JH-Pcis 23 Hz, $\mathrm{J}_{\mathrm{H}-\mathrm{Rh}} 10 \mathrm{~Hz}$ ), is indicative of the hydride occupying an apical position trans to either a phosphine or phosphite, as opposed to a $\mathrm{CO},{ }^{15 \mathrm{f}}$ and the smaller $\mathrm{J}_{\mathrm{H}-\mathrm{Pcis}}$ coupling is seen in the ${ }^{31 P}$ NMR of the phosphite signal therefore the phosphite is cis to the hydride. This axial-equatorial species, with the hydride trans to the phospholane, can also be detected as a resting state during catalysis via in situ HPIR (Figure S7).

Upon addition of allylbenzene to preformed hydrido dicarbonyl complex 3 under pressure of $\mathrm{CO}$, a new absorbance at $1693 \mathrm{~cm}^{-1}$ was observed with concomitant shift of the Rh-CO stretches to $2024 \mathrm{~cm}^{-1}$ and $1985 \mathrm{~cm}^{-1}$ (Figure 3). These are assigned as the acyl dicarbonyl species 9. The band at $1693 \mathrm{~cm}^{-1}$ can be just about observed via HPIR spectroscopy during hydroformylation under catalytic conditions, although it is quickly lost under the large product aldehyde band at $1738 \mathrm{~cm}^{-1} .18$ The most abundant reaction intermediate observed during hydroformylation is hydrido dicarbonyl 3 , the bands of which are prominent throughout the reaction, in line with the first order behaviour in alkene.

The observation of acyl 9 during catalysis is also in line with the positive order behaviour observed for $\mathrm{H}_{2}$ suggesting 9 is a second, minor, turnover determining intermediate of the catalytic cycle.

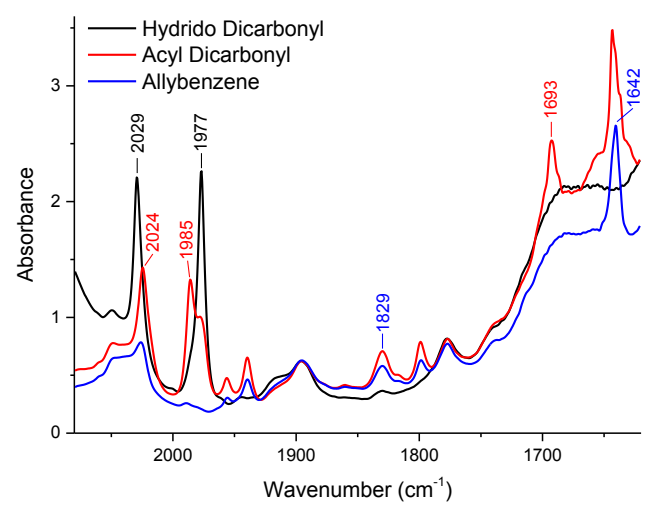

Figure 3: HPIR overlay showing characteristic bands of rhodium acyl dicarbonyl species 9 formed on addition of allylbenzene to preformed hydrido dicarbonyl 3 under pressure of $\mathrm{CO}$.

Acyl dicarbonyl 9 can be detected by NMR at ambient temperature and pressure of $\mathrm{CO}$; the species are quite stable, albeit with some equilibration to the thermodynamically favoured linear acyl dicarbonyl 91 occurring. Via ${ }^{31} \mathrm{P}\left\{{ }^{1} \mathrm{H}\right\}$ NMR two major species can be observed, both upfield from the hydrido dicarbonyl complex, and are assigned as branched and linear acyl dicarbonyl species 9b and 9l (Scheme 5). These complexes exist as a distinct doublet of doublets in the phosphite region with equally sharp but overlapping signals in the phospholane region. The minor 
diastereomer of $\mathbf{9 b}$ could not be observed, but this is perhaps unsurprising as reaction ers are typically around 93:7.

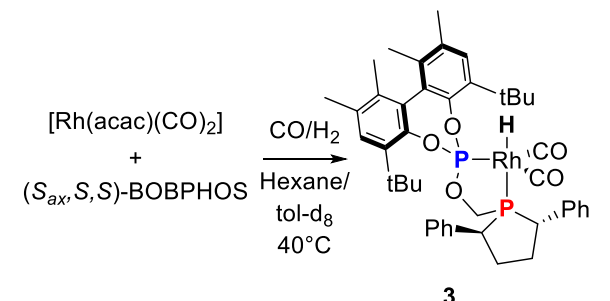

a)
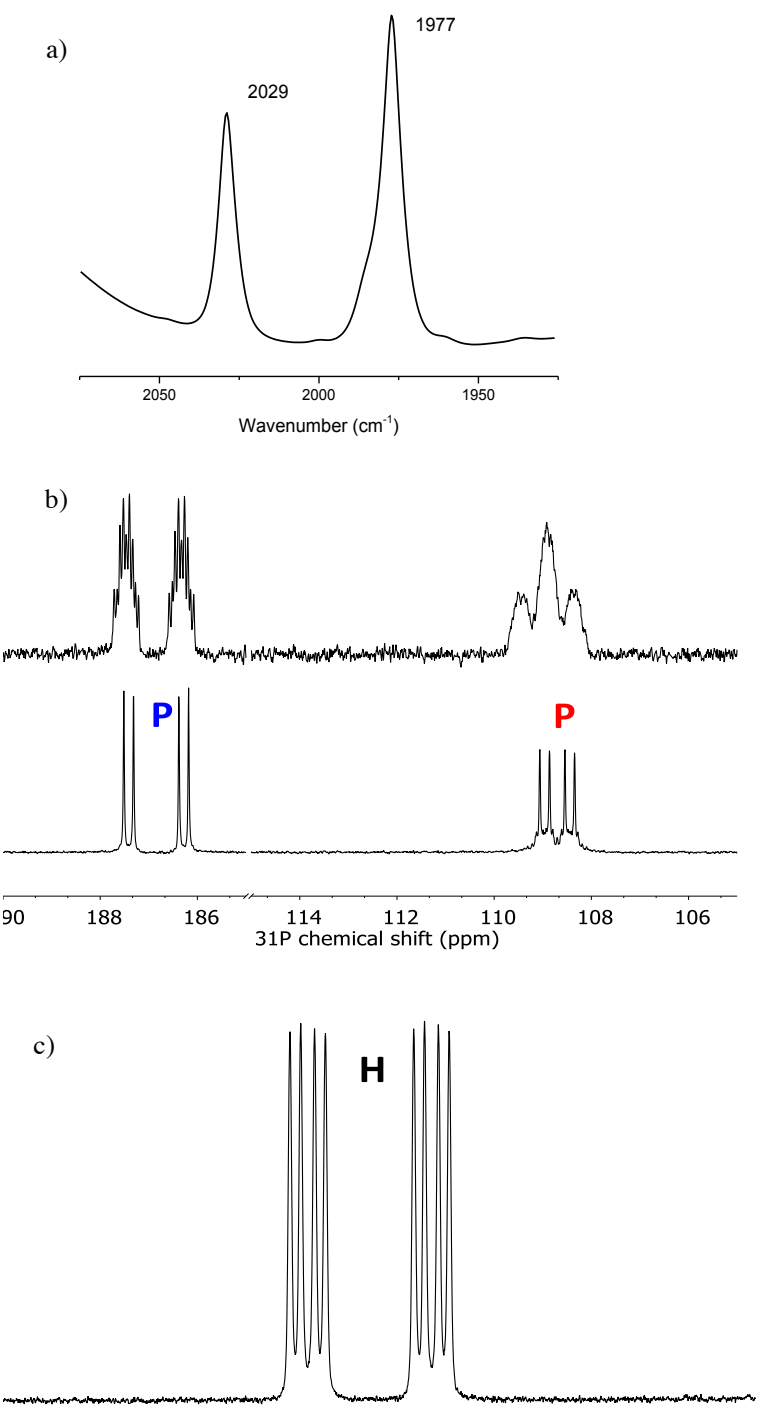

$\begin{array}{llllllllllllll}7.6 & -7.7 & -7.8 & -7.9 & -8.0 & -8.1 & -8.2 & -8.3 & -8.4 & -8.5 & -8.6 & -8.7 & -8.8 & -8.9 \\ 1 H & & \end{array}$

Scheme 4: Characterization of Rh/BOBPHOS hydrido dicarbonyl complex 3 by HPIR and NMR. (a) Spectra showing unsymmetrical nature of carbonyl bands at 2029 and $1977 \mathrm{~cm}^{-1}$ (hexane, 4 bar $\mathrm{CO} / \mathrm{H}_{2}, 40{ }^{\circ} \mathrm{C}$ ); (b) ${ }^{31} \mathrm{P}\left\{{ }^{1} \mathrm{H}\right\}$ and ${ }^{31} \mathrm{P}$ NMR spectra (202.5 MHz, RT) of the phosphite (P) and phospholane regions (P); (c) ${ }^{1} \mathrm{H}$ NMR (500 MHz, RT) of the hydride region (H).
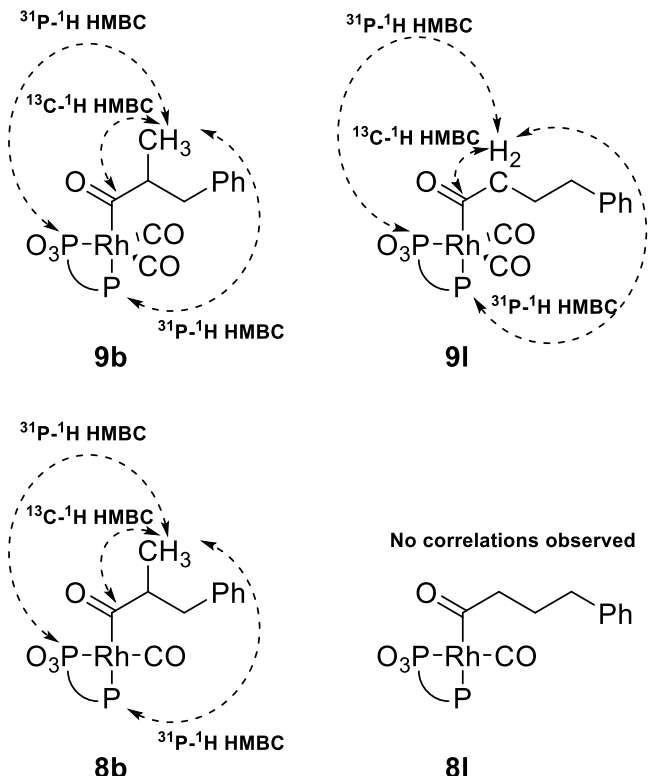

No correlations observed

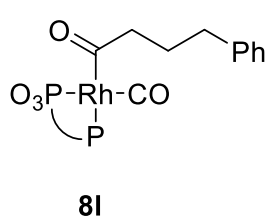

Scheme 5: Branched and linear rhodium acyl species 8 and 9 of allylbenzene as observed and characterised by multinuclear NMR. ${ }^{18}$

Jhh-P coupling constants of $c a .250 \mathrm{~Hz}$ for the phosphite and ca. $75 \mathrm{~Hz}$ for the phospholane suggests the same unchanged equatorial-axial coordination and trigonal bipyramidal geometry as observed for hydrido dicarbonyl 3. ${ }^{31} \mathrm{P}-{ }^{1} \mathrm{H}$ HMBC allows assignment of each regioisomer via correlations from both phosphorous atoms of the ligand to a doublet at $\delta 0.83 \mathrm{ppm}$ for $\mathbf{9 b}$ and a triplet of doublets at $\delta$ $2.81 \mathrm{ppm}$ for 9l. In turn, these proton signals exhibit further correlations via ${ }^{13} \mathrm{C}-{ }^{1} \mathrm{H}$ HMBC to doublet of doublet ${ }^{13} \mathrm{C}$ signals at $\delta 237.0 \mathrm{ppm}$ and $\delta 229.4 \mathrm{ppm}$ for $\mathbf{9 b}$ and 91 respectively; such a far-downfield shift is characteristic of a rhodium acyl carbon. ${ }^{24}$ Both acyl carbons display JC-P coupling constants of $c a$. $74 \mathrm{~Hz}$ as well as JRh-c couplings of $c a$. $18 \mathrm{~Hz}$. Finally, 1D selective NOESY allowed characterization of proton signals along the alkyl backbone of both acyl dicarbonyl species.

Two further species are present in ${ }^{31} \mathrm{P}$ NMR, and we tentatively assign these as the 4-coordinate branched, $\delta 179.0$ and $\delta 81.8 \mathrm{ppm}$, and linear, $\delta 181.1$ and $\delta 86.2 \mathrm{ppm}$, acyl monocarbonyl species $\mathbf{8 b}$ and $\mathbf{8 1}$ (Scheme 5). These exist as a 2:1 4- vs 5-coordinate ratio for the branched and 1:1 for the linear acyls. There is a drastic change in their $J_{\mathrm{Rh}-\mathrm{P}}$ coupling constants, $c a .126 \mathrm{~Hz}$ in the phosphite region and $159 \mathrm{~Hz}$ in the phospholane region, suggesting the species is not 5 -coordinate but rather a 4-coordinate square planar geometry with strong field ligand directly trans to $\mathrm{P}$. ${ }^{31} \mathrm{P}-1 \mathrm{H}$ HMBC shows correlations from 4-coordinate $\mathbf{8 b}$ phosphite at $\delta 179.0 \mathrm{ppm}$ to a ${ }^{1} \mathrm{H}$ doublet at $\delta 0.93 \mathrm{ppm}$. In turn, this doublet shows a further ${ }^{13} \mathrm{C}-{ }^{1} \mathrm{H}$ HMBC correlation to a doublet of doublets ${ }^{13} \mathrm{C}$ signal at $\delta 252.0 \mathrm{ppm}$, suggesting an acyl rather than alkyl species, with largely similar JcRh of $18 \mathrm{~Hz}$ but much increased JC-P coupling of $129 \mathrm{~Hz}$. No relevant multinuclear cross peaks could be observed for what is assumed to be the linear acyl monocarbonyl $\mathbf{8 1}$.

Table 2 shows the ratio of the ${ }^{31} \mathrm{P}$ NMR peaks of acyl dicarbonyl $\mathbf{9 b}$ and $\mathbf{9 l}$ formed from the addition of allylbenzene to hydrido dicarbonyl 3 under CO. The pressure of CO used during the formation $\mathbf{9 b}$ and $\mathbf{9 l}$ has a direct effect on 
Table 2: Comparison of ratios of acyl species $9 b$ and 91 formed under stoichiometric conditions and at increasing pressures of $\mathrm{CO}$ including the resulting product aldehyde ratio when turnover is completed using either pressure of syngas or $\mathrm{H}_{2}$.

\begin{tabular}{|c|c|c|c|c|c|}
\hline Entry & $\mathrm{b}_{\text {ald }}: \mathrm{l}_{\text {ald }}(\mathrm{b} / \mathrm{l})^{\mathrm{a}}$ & & $9 \mathrm{~b}: 9 \mathrm{l}(\mathrm{b} / \mathrm{l})^{\mathrm{b}}$ & & $\mathrm{b}_{\text {ald }}: \mathrm{l}_{\text {lad }}(\mathrm{b} / \mathrm{l})^{\mathrm{a}}$ \\
\hline 1 & $60.0: 40.0(1.5)$ & $\mathrm{H}_{2}{ }^{\mathrm{c}}$ & 75.0:25.0 (3:1) & $\mathrm{CO} / \mathrm{H}_{2}{ }^{\mathrm{C}}$ & $74.0: 26.0(2.8)$ \\
\hline 2 & $50.5: 49.5(1.0)$ & $\mathrm{H}_{2}{ }^{\mathrm{c}}$ & $\begin{array}{l}71.5: 28.5(2.5) \\
P_{C O}=2 \mathrm{bar}\end{array}$ & $\stackrel{\mathrm{CO} / \mathrm{H}_{2}{ }^{\mathrm{C}}}{\longrightarrow}$ & $67.0: 33.0(2.0)$ \\
\hline 3 & $38.5: 61.5(0.6)$ & $\mathrm{H}_{2}{ }^{\mathrm{c}}$ & $\begin{array}{l}52.5: 47.5(1.1) \\
P_{C O}=1 \text { bard }\end{array}$ & $\stackrel{\mathrm{CO} / \mathrm{H}_{2}{ }^{\mathrm{C}}}{\longrightarrow}$ & $51.5: 48.5(1.1)$ \\
\hline
\end{tabular}

a) As determined by ${ }^{1} \mathrm{H}$ NMR spectroscopy; ${ }^{\text {b) }}$ as determined by ${ }^{31} \mathrm{P}$ NMR spectroscopy; ${ }^{\mathrm{Cl}} 4 \mathrm{bar}, 40^{\circ} \mathrm{C}, 2 \mathrm{~h}$; ${ }^{\text {d) }}$ ambient pressure of CO from balloon.

their observable ratio with an increase in branched to linear ratio on increasing the CO pressure. Although we note that the ratio between 4 - and 5-coordinate acyl species remains at $2: 1$ for $\mathbf{9 b : 8 b}$ and $1: 1$ for $\mathbf{9 l : 8 1}$ within this pressure range. Providing the pressure of $\mathrm{CO}$ is not reduced below the partial pressure used in hydroformylation, the exhibited branched selectivity of the acyl species closely resembles that of the product aldehydes formed under catalytic conditions (Table 1). Further, on subjecting the acyl mixture to pressure of syngas forms aldehydes with branched to linear ratios typical for the catalytic reaction.

When the acyl species are subjected to pressure of hydrogen alone the regioselectivity of the aldehyde is significantly reduced, suggesting a substantial isomerization to the linear acyl occurring in the absence of CO. Such behaviour is consistent with recent work by Landis and co-workers on the BisDiazaphospholane ligand, ${ }^{25}$ where it was shown that only during a low CO pressure regime did catalyst speciation correspond, at least superficially, to a CurtinHammett kinetic regime involving $\mathbf{9 b}$ and $\mathbf{9 l}$ as rapidly isomerising intermediates. Pressure of $\mathrm{CO}$ suppresses this isomerisation; the lowered selectivity is also observed when the acyl species is formed under ambient pressure of CO (entry 3) giving an almost 50:50 mixture of $\mathbf{9 b}$ and $\mathbf{9 l}$.

The close correlation between the relative ratios of acyl diastereomers and product regioisomers is consistent with hydrogenolysis having no positive influence on the regioselectivity of the reaction. In particular, as there were no scenarios where the branched selectivity of aldehyde product was higher than that of the branched acyl, we can conclude the regioselectivity determining event is prior to hydrogenolysis.

\section{Deuterium Labelling Study}

To further assess the impact of hydrogenolysis on selectivity under catalytic conditions, a labelling study was carried out. The objective was to probe the reversibility of migratory insertion of the Rh-hydride to alkene, particularly for the linear Rh-alkyl intermediate $6 \mathbf{6 l}$. If the unique regioselectivity were primarily caused by the inability of linear intermediates to deliver linear aldehydes (challenging insertion of $\mathrm{CO}$ or hydrogenolysis) then linear Rh-alkyl $\mathbf{6 l}$ formation would have to be highly reversible, and the majority of branched aldehydes formed would be from alkene having entered the catalytic cycle more than once. On the other hand, the stoichiometric experiments point towards regioselectivity coming directly from preferential formation of branched Rh-alkyl $\mathbf{6 b}$. To this end, hydroformylation was conducted with deuterated starting material 1-allyl-d $\mathrm{d}_{5}-4$-(tert-butyl)benzene, 11a. This compound could be prepared by cross coupling of 4-tertbutylbenzene boronic acid with $d 5$-allyl bromide. ${ }^{18}$

If hydride transfer proved irreversible then only two hydrides would be found in either branched or linear products, 11a-B and 11a-L (Scheme 6). However, if hydride transfer were reversible then a hydride could be scrambled in the starting material at either the terminal or 2 position of the alkene depending on whether probranched, 11b, or prolinear, 11c, pathways were reversible.

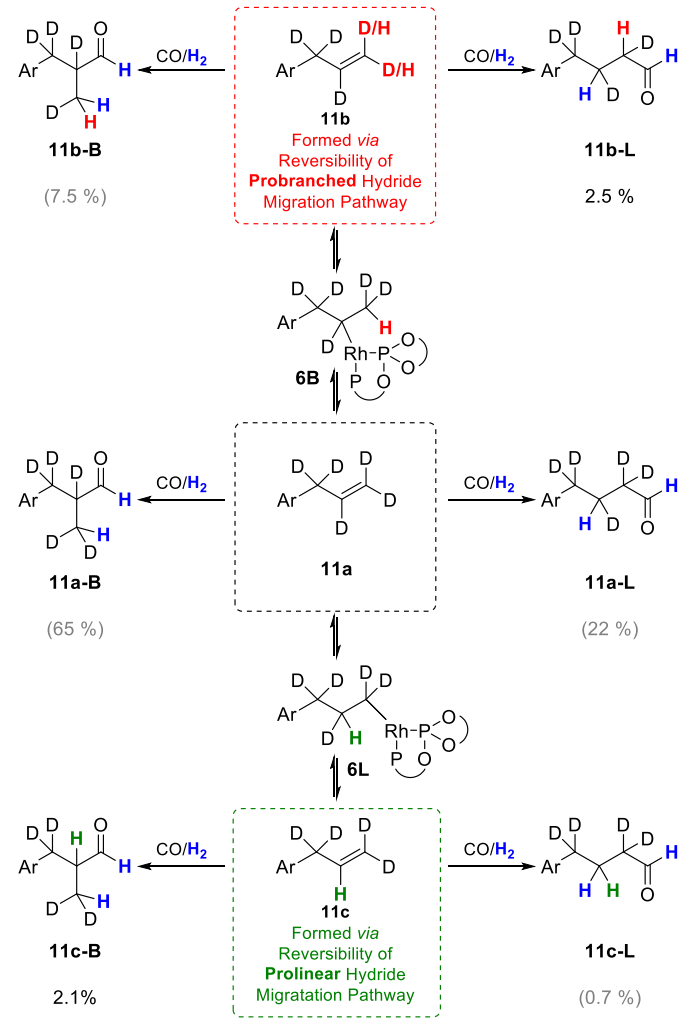

Scheme 6: Products of hydroformylation of 11a and their hydride substitution patterns if reversibility of either pathways occurs. Values are percentage of total aldehyde product, those in parenthesis are extrapolated assuming the final 75:25 branched to linear selectivity of the product holds throughout. 


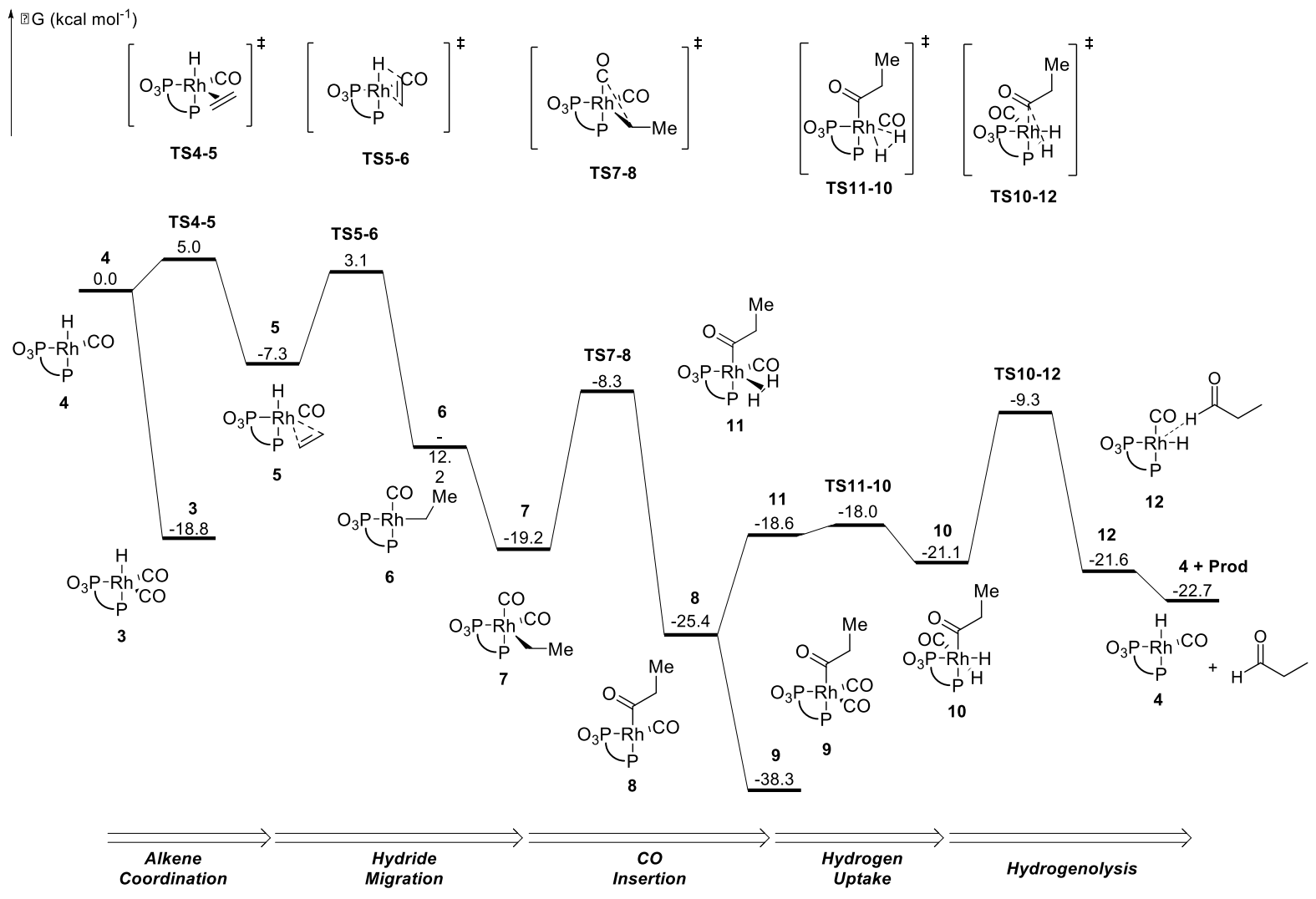

Figure 4: Potential energy surface of the full catalytic cycle for Rh/BOBPHOS and ethene showing the lowest energy pathway.

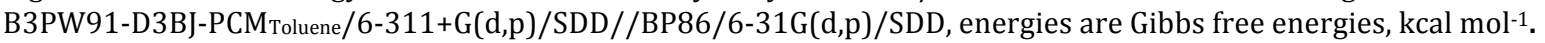

These scrambled starting materials could then re-enter the catalytic cycle to form aldehyde products of differing hydride substitution,11b-B and 11b-L, and 11c-B and 11C-L, with products $\mathbf{1 1 b}-\mathbf{L}$ and $\mathbf{1 1 c}-\mathbf{B}$ containing uniquely detectable and quantifiable hydrides via ${ }^{1} \mathrm{H}$ NMR. It was not possible to directly measure the deuterium incorporation in all the aldehyde isomers formed, though these can be estimated assuming branched selectivity for $\mathbf{1 1 b}$ and 11c are each equal to the total aldehyde branched selectivity of 3:1 (values in parentheses in Scheme 6). Fortunately, it was possible to directly measure the amount of aldehyde 11c-B.

Catalyst activation was performed in the normal manner and hydroformylation of the deuterium labelled substrate 11a was conducted at reaction conditions of $30^{\circ} \mathrm{C}, 5$ bar syngas, toluene, $0.4 \mathrm{~mol} \% \mathrm{Rh}, \mathrm{L}: \mathrm{Rh}=1.25$ to give $78 \%$ conversion and an overall branched to linear ratio of 75:25 (3.0) after 43 hours, comparable with our previous results of hydroformylation of this substrate.

For a later step of the catalytic cycle, such as hydrogenolysis, to be the dominant factor in controlling branched regioselectivity would require 11c-B, derived from $\beta$ deuteride elimination from linear Rh-alkyl species $\mathbf{6 l}$ and passing through 11c, to be the major component in the reaction mixture. However, integration of ${ }^{1} \mathrm{H}$ NMR spectra reveals that only $2.1 \%$ of the total aldehyde composition is 11c-B (2.5\% of 11b-L was also directly quantified). Since $\beta$-hydride/deuteride elimination will be subject to a kinetic isotope effect, the $2.1 \%$ will underestimate the amount of branched aldehyde being formed from a linear alkyl intermediate. A kinetic isotope effect favouring elimination of $\mathrm{H}$ over $\mathrm{D}$ by $2: 1$ has been determined in the literature. ${ }^{26}$
While we cannot directly measure the KIE for this specific system an unprecedented KIE of 40 or more would be required in order to argue that most of the branched aldehyde had arisen from the reversibility of the linear $\mathrm{Rh}$ alkyl 61. In conclusion, all of the results point towards the branched selectivity being set at an early stage of the catalytic cycle.

\section{Computational Modelling}

We turned to DFT to attempt to further clarify the roles of hydride transfer and hydrogenolysis in determining the outcome of the reaction. Our theoretical work first explored the full catalytic cycle using ethene as a simple model substrate (Figure 4). All 5-coordinate structures are of an equatorial-axial coordination with the phospholane of BOBPHOS in the apical position (vide supra). There is a preference for one isomer with regards to the relative positions of the reactive ligands relative to the phospholane or the phosphite. Reaction at both possible positions have been explored and the lowest energy pathway is shown. ${ }^{18}$ The transition state for hydrogenolysis TS10-12 (29.0 kcal $\mathrm{mol}^{-1}$ above 9) has a larger activation energy than either alkene insertion TS4-5 (23.8 kcal mol-1 above 3) or hydride transfer TS5-6 (21.9 kcal mol-1 above 3$)$. The activation barrier for CO insertion TS7-8 (10.9 kcal mol-1) is significantly below the other energy barriers of the cycle and hydrogen uptake, TS11-10, is exceedingly facile. Uptake of CO from 6 to 7 was found to be without barrier on the potential energy surface. ${ }^{18}$ The origin of this large activation barrier for hydrogenolysis rests in part on the considerable thermodynamic stability of the off-cycle intermediate acyl dicarbonyl $9\left(-38.3 \mathrm{kcal} \mathrm{mol}^{-1}\right)$, significantly lower in energy than 


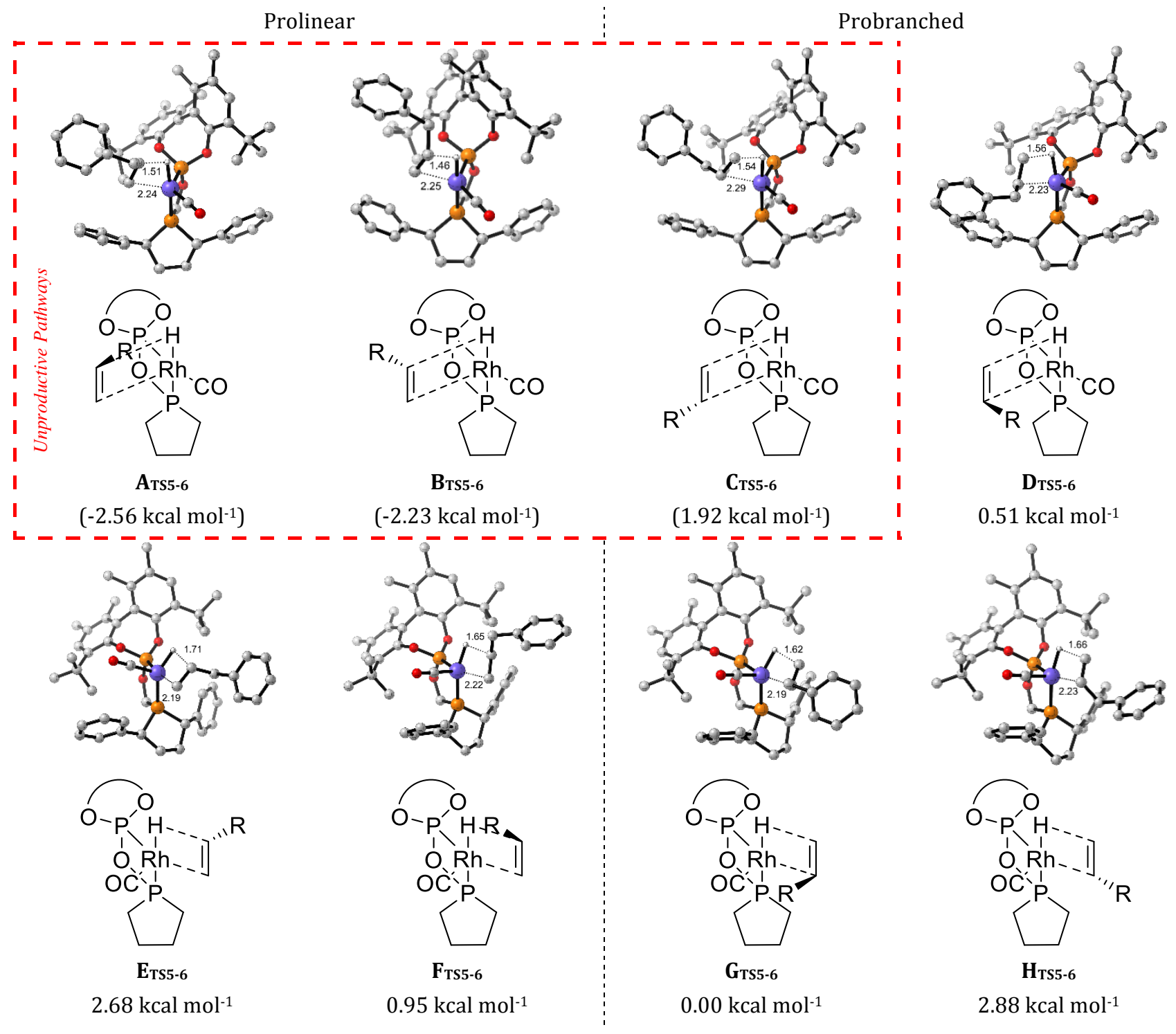

Figure 5: Optimised geometries and relative free energies for hydride transfer transition state TS5-6, showing eight possible orientations of allylbenzene, hydrogen atoms have been omitted for clarity. Theoretical reaction analysis performed at B3PW91-D3PCMToluene/6-311+G(d,p)/SDD//BP86-D3/6-31G(d,p)/SDD, energies are Gibbs free energies, kcal mol-1.

preceding off-cycle intermediate hydrido dicarbonyl 3 ($18.8 \mathrm{kcal} \mathrm{mol}^{-1}$ ). The thermodynamic sink presented by complex 9 is consistent with the observation of the acyl complex in allylbenzene hydroformylation monitored via HPIR spectroscopy. The computational results suggest that,for ethene, hydrogenolysis TS10-12 is the sole turnover determining transition state (TDTS) and acyl dicarbonyl 9 the sole turnover determining intermediate (TDI).

To gain a deeper insight into the origin of the high branched aldehyde selectivity displayed by BOBPHOS, we performed a detailed DFT study on the catalytic cycle of allylbenzene hydroformylation. The availability of two possible coordination sites, facial selectivity, and alkene orientation results in probranched and prolinear pathways and a total of eight transition states, A-H, for each step prior to rhodium-alkyl 7 formation. Figure 5 shows the optimized geometries and relative energies for each of the eight transition states of hydride transfer.

Our calculations showed that the transition states for hydride migration via prolinear pathways ATs5-6 and BTs5-6 are the lowest in energy, with $\mathbf{A}_{\text {Ts5-6 }}$ favoured over the lowest probranched transition state $\mathbf{G}_{\text {Ts5-6 }}$ transition state by $2.56 \mathrm{kcal} \mathrm{mol}^{-1}$. However, on placing these transition states in the context of the catalytic cycle via intrinsic reaction coordinate (IRC) calculations pathways $\mathbf{A}$ and $\mathbf{B}$ (as well as probranched pathway $\mathbf{C}$ ) were found to be unproductive.

This is the case because pathways $\mathbf{A}$ to $\mathbf{C}$ cannot move from the initially quite stabilized transition state to reach 6. At the RI-BP86 level of optimisation, these only lead to trigonal bipyramidal intermediates with a $\beta$-agostic interaction $^{27}$ between the $\mathrm{Rh}$ and the former hydride (Figure S47), rather than the square planar rhodium-alkyl monocarbonyl complex 6 that is required for catalysis. Despite having lower energy transition states than the productive TS5-6, the $\beta$-agostic intermediates (labeled 6') that arise from $\mathbf{A}_{\text {T55-6 }}$ and $\mathbf{B}_{\text {T55-6 }}$ are actually higher in free energy than the transition states leading to them (Figure S46 in the ESI). Thus, these intermediates are unlikely to exist on the higher-level energy surfaces and, if such structures were formed by accidental thermal fluctuations, would be 
expected to revert back to the olefin complexes $\mathbf{5}$ without barrier. All attempts to locate any transition state that leads from such $\beta$-agostic intermediates, $\mathbf{6}^{\prime}$, forward to the productive pathway failed. Further discussion on the unfeasibility of the $\beta$-agostic intermediates possessing any energetically favourable transition states is discussed on page 39 of the ESI. Figure 6 also shows the key differences between productive $\mathbf{G}_{\text {TS5-6 }}$ and unproductive $\mathbf{A}_{\text {TS5-6 }}$ pathways to reach 6. In the case of the latter, the substrate is stabilized on the wrong side of the Ph-phospholane ring relative to the position the alkyl occupies in square planar 6. This creates an insurmountable physical barrier.
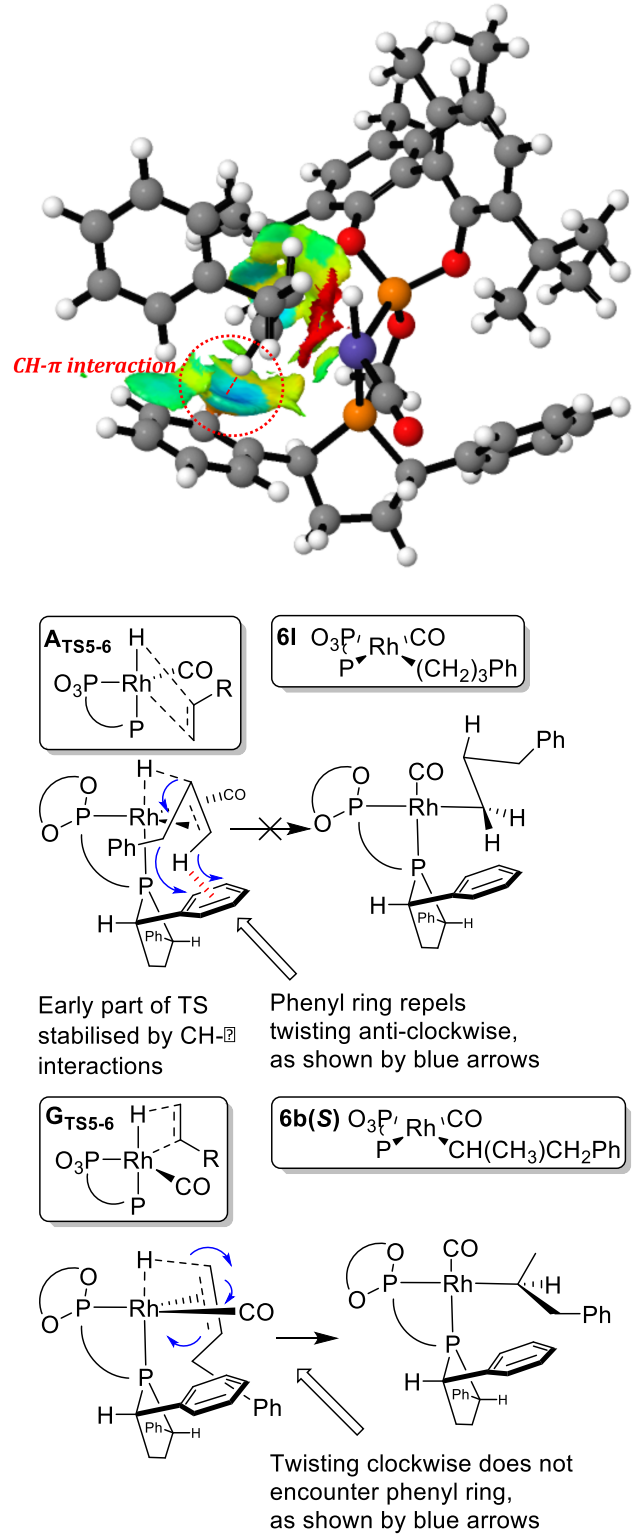

Figure 6 (top): $\quad$ B3PW91-D3-PCM Toluene/6$311+\mathrm{G}(\mathrm{d}, \mathrm{p}) / \mathrm{SDD} / / \mathrm{BP} 86-\mathrm{D} 3 / 6-31 \mathrm{G}(\mathrm{d}, \mathrm{p}) / \mathrm{SDD}$ representative substrate-ligand NCI surface of prolinear ATs5-6 showing the important stabilising $\mathrm{CH}-\pi$ interaction, further NCI surfaces can be found in Figure S48. The colour spectrum ranges from blue (strongly attractive) to green (weekly attractive) to yellow (mildly repulsive) to red (strongly repulsive). (Bottom) Scheme comparing the blocked unproductive pathway to $\mathbf{6 1}$ from ATs5-6 relative to the straightforward formation of $6 \mathbf{b}(S)$ from GTS5-6.
All three unproductive transition states appear to be stabilised by strong $\mathrm{CH}-\pi$ interactions between the substrate and proximal phenyl moiety of the phospholane. A noncovalent interaction (NCI) descriptor based on electron density, developed by the Johnson and Contreras-García groups, ${ }^{28}$ allows a qualitative visual analysis of NCIs and is shown here to be a useful tool. The coloration of the NCI surface allows identification and characterization of attractive and repulsive interactions; a strong attractive interaction is blue, van der Waals and dispersion interactions are in green, and de-stabilising steric interactions are in red. Figure 6 shows prolinear $\mathbf{A}_{\text {TS5-6 }}$ as a representative example (other NCI surfaces can be found in Figure S48).

Non-bonding interactions between catalyst and substrate are known to play an important, and sometimes crucial, role in the prediction and explanation of high degrees of selectivity in asymmetric catalysis. ${ }^{29}$ However, in this case the very same ligand-substrate attractive non-bonding interactions that particularly stabilize the transition state for $\mathrm{C}-\mathrm{H}$ bond forming in trigonal bipyramidal ATs5-6 only serve to form a pocket in which it is not possible to twist into the require square planar intermediate $6 \mathbf{6}$. To do so essentially requires the whole substrate to be threaded through the space occupied by the Ph ring on the phospholane. In contrast, it is straightforward for the transition states that arise from the alkene exchanging with the other CO ligand, $\mathbf{E}_{\text {TS5-6 }}$ through to $\mathbf{G}_{\text {TS5-6 }}$ to twist in the opposite direction and reach the intermediate 6 .

The origin of regio- and enantioselectivity during hydride transfer, TS5-6, can be represented by a threedimensional quadrant model such that both coordination sites are represented as two faces on a cube (Figure 7). Substrate orientations for branched product pathways are shown, for the linear product pathway the alkene needs only be rotated 180 degrees around the alkene-Rh axis.

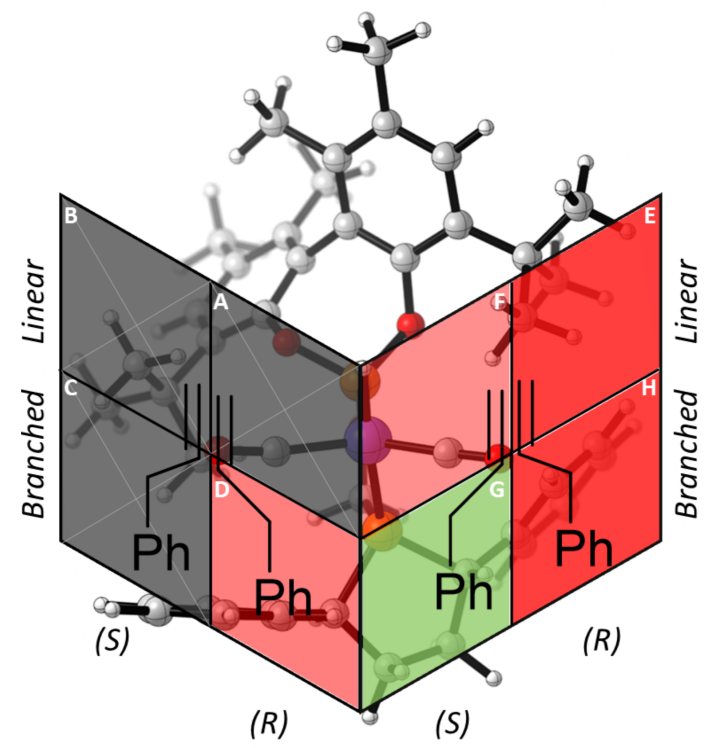

Figure 7: Three-dimensional quadrant representation of hydrido dicarbonyl 3 and substrate showing the possible orientations of branched product pathways. Unproductive branched and linear pathways are represented by the quadrant where $\mathrm{CH}_{2} \mathrm{Ph}$ would reside in crossed out grey, strong steric repulsion in dark red, mild steric hindrance in light red, and the major $(S)$-branched pathway in green. 

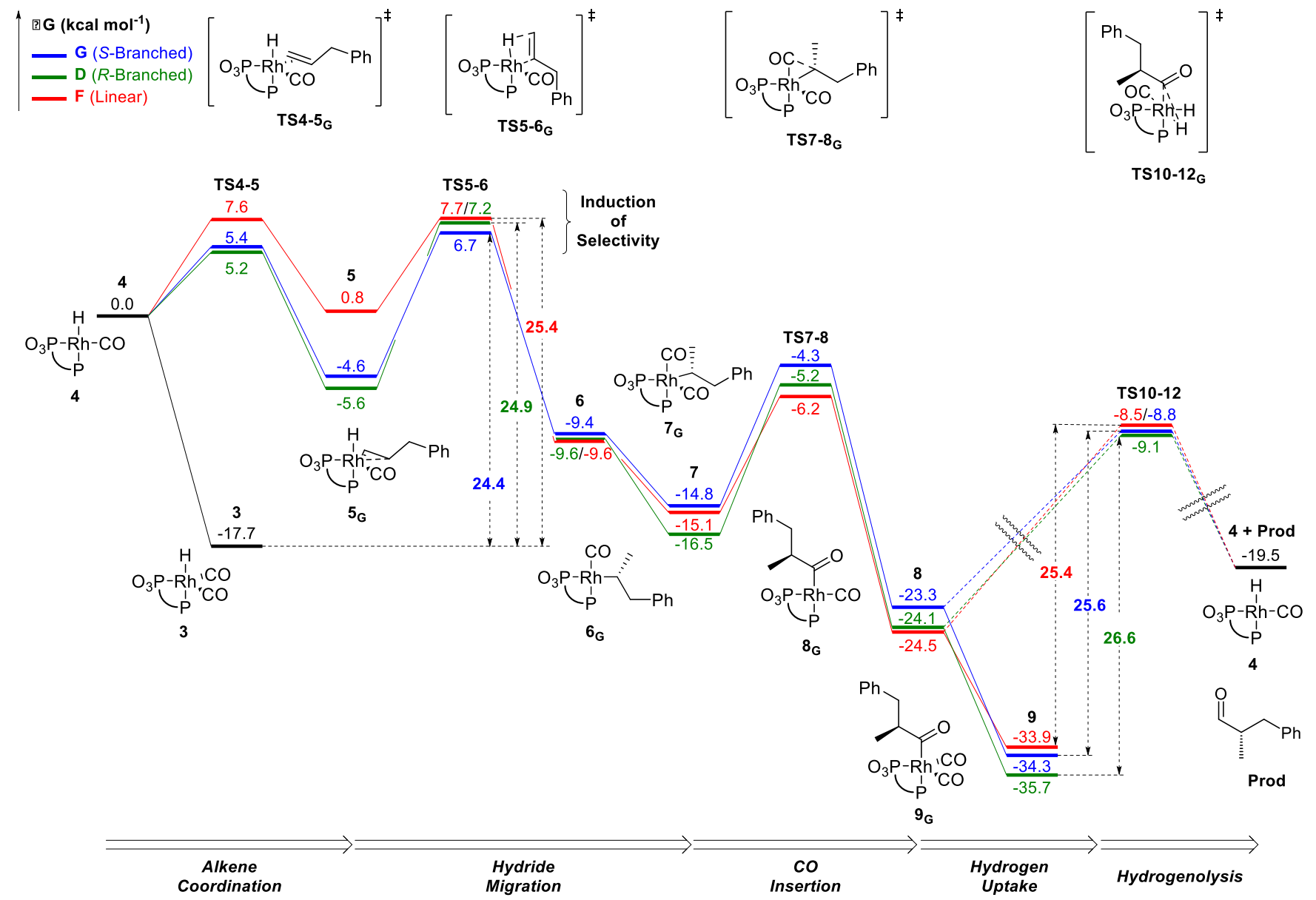

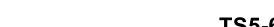

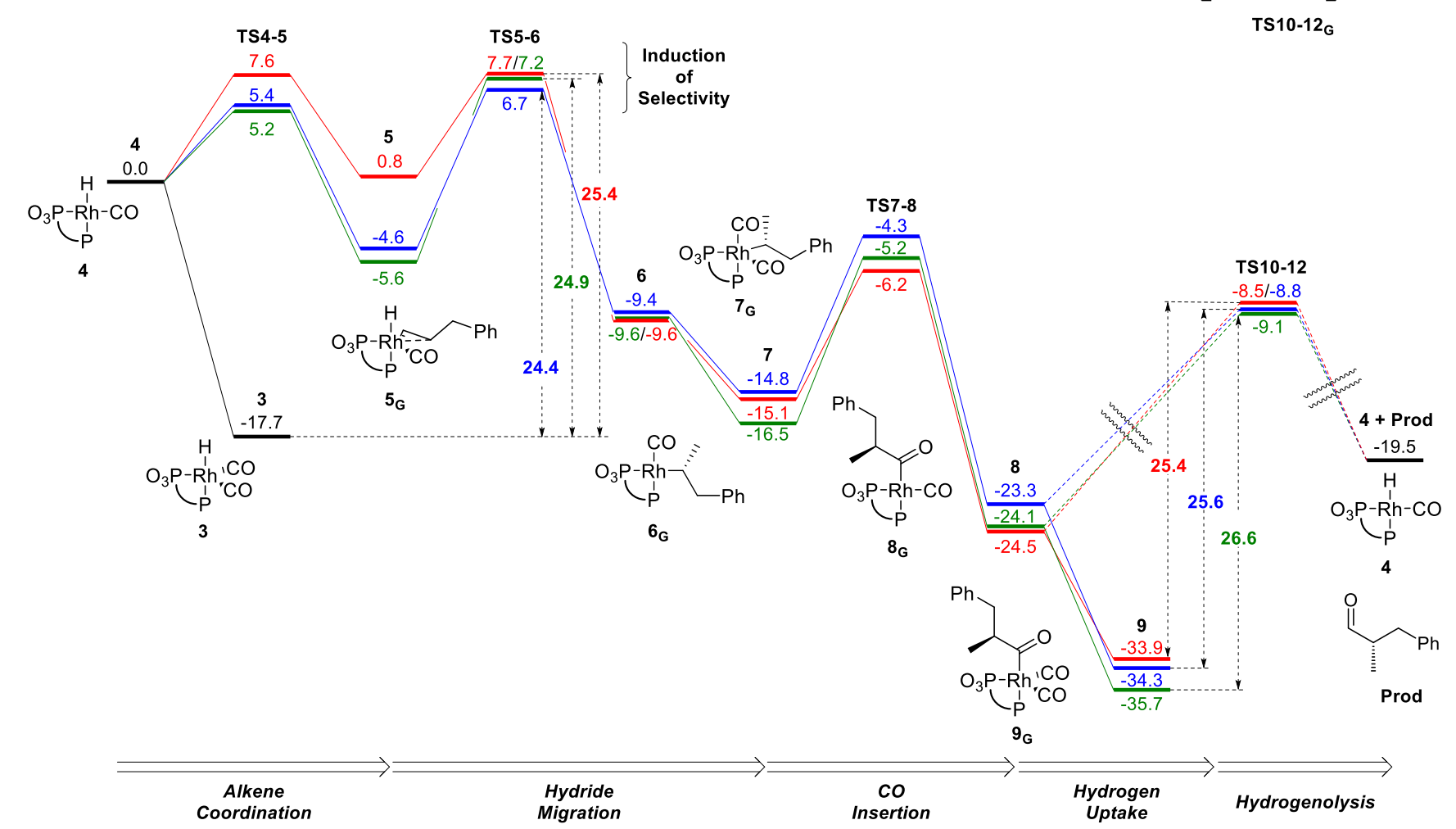

TS10-12 G

Figure 8: Free energy profiles of the major $(S)$-branched (pathway G, blue), minor $(R)$-branched (pathway D, green), and linear (pathway F, red) reaction pathways. Theoretical reaction analysis performed at B3PW91-D3-PCMToluene/6311+G(d,p)/SDD//BP86-D3/6-31G(d,p)/SDD, energies are Gibbs free energies in kcal mol-1. The dashed lines represent low-lying TS and intermediates, that were not calculated (see fig. 4).

The three transition states leading to unproductive pathways are crossed out in grey. The most sterically encumbered quadrants are shown in dark red, the remaining mildly hindered light red quadrants lead to the linear and $R$-branched products while the unhindered green quadrant leads to the major $S$-branched product. Of the five productive transition states, two are disfavoured by $>2.5$ kcal mol-1 each. For probranched $\mathbf{H}_{\text {Ts5-6 }}$ ( $2.88 \mathrm{kcal} \mathrm{mol}^{-1}$ ) this is due to the close proximity and resulting steric clash between the benzylic $\mathrm{CH}_{2}$ of the substrate and a pseudoaxial benzylic proton on the phospholane ring.

Prolinear $\mathbf{E}_{\text {Ts5-6 }}$ (2.68 $\mathrm{kcal} \mathrm{mol}^{-1}$ ) is also unfavoured due to a steric interaction with the adjacent tert-butyl group and phenyl moiety. The remaining lowest energy transition states lead to a calculated branched to linear selectivity of 83:17 (4.9) and favour the $(S)$-enantiomer in a 70:30 er, which, in the context of a subtle process such as this, is in full agreement with experimental results, 79:21 (3.8) and 94:6 $(S)$ er. We can conclude that the validity of the DFT calculations are supported by reproducing the observed bias towards branched aldehyde formation and a bias in favour of the $(S)$-enantiomer.

Expanding these findings beyond allylbenzene by using only these three lowest energy transition states resulted in further reproduction of trends between experimental results and predicted selectivities (Table S5). 4,4-dimethyl-1- pentene is a challenging substrate experimentally with branched selectivity dropping to $41: 59$ (0.7); this switch to slight linear selectivity was reproduced by our calculations, 42:58 (0.7). The transition states leading to the major $(S), \mathbf{G}_{\text {TS5-6, }}$ and minor $(R), \mathbf{D}_{\text {TS5-6, }}$, branched enantiomers result from alkene coordination to different sites. $\mathbf{D}_{\text {Ts5-6 }}$ is

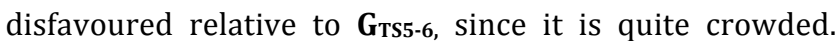
Nonetheless in $\mathbf{D}_{\text {Ts5-6 }}$ the substrate is placed outside of the unproductive stabilizing pocket encountered in $\mathbf{A}_{\text {Ts5-6 }}$ and $\mathbf{B}_{\text {TS5-6 }}$ and hence twisting into $\mathbf{6 b}(R)$ is possible without jumping the impossible hurdle of the Ph-phospholane ring. The transition states leading to the major branched enantiomer, $\mathbf{G}_{\text {TS5-6, }}$ and linear products, $\mathbf{F}_{\text {TS5-6, result from coor- }}$ dination of opposite faces of the prochiral alkene.

When examining the geometries of the transition states at different coordination sites, A-D $\mathbf{D}_{\text {TS5-6 }}$ and $\mathbf{E}-\mathbf{H}_{\text {Ts5-6, }}$, we observe that whereas $\mathbf{A}-\mathbf{D}_{\text {TS5-6 }}$ are close to ideally trigonal bipyramidal, E-HTs5-6 are closer to an ideally square pyramidal geometry, with the $\mathrm{CO}$ in the apical position and the $\mathrm{Rh}-\mathrm{C}$ bond of the substrate close to 180 degrees to the phosphite, although these geometries don't directly play any role in the selectivity of catalysis. (Table S6).

The free energy profiles for the three product forming pathways, major (S)-branched (pathway G, blue), minor $(R)$-branched (pathway $\mathbf{D}$, green), and linear (pathway $\mathbf{F}$, red), are shown in Figure 8. In line with the findings on the 
study of ethene as substrate (Figure 4) hydrogen uptake TS11-10 was ignored as energetically unimportant. Additionally, the specific $\mathrm{CO}$ or hydride that undergoes $\mathrm{C}-\mathrm{C}$ or $\mathrm{C}-\mathrm{H}$ bond formation was also derived from the ethene pathway. CO insertion TS5-6, although kinetically unimportant, is a linear selective process $\left(\Delta \mathrm{G}^{\ddagger} 11.5 \mathrm{kcal} \mathrm{mol}^{-1}\right.$ in comparison to $12.5 \mathrm{kcal} \mathrm{mol}^{-1}$ for the $(R)$-branched pathway and $13.4 \mathrm{kcal} \mathrm{mol}^{-1}$ for the $(S)$-branched pathway).

For the formation of all reaction products, the energy span for hydrogenolysis is slightly greater than that required for hydride transfer, $\Delta \Delta \mathrm{G}^{\ddagger} 1.2 \mathrm{kcal} \mathrm{mol}^{-1}$ for pro- $(S)$-branched pathway G, $1.7 \mathrm{kcal} \mathrm{mol}^{-1}$ for pro- $(R)$-branched pathway $\mathbf{D}$, and $0.04 \mathrm{kcal} \mathrm{mol}^{-1}$ for prolinear pathway $\mathbf{F}$. With the energy margins involved so small, the degree of TOF control analysis of the energy span model of Kozuch and Shaik ${ }^{30}$ suggests that two intermediates, hydrido dicarbonyl $\mathbf{3}$ and acyl dicarbonyl 9, and two transition states, hydride transfer TS5-6 and hydrogenolysis TS10-12, share the roles of TDIs and TDTSs. In fact, for prolinear pathway $\mathbf{F}$, the energy spans for alkene coordination, TS4-5, hydride insertion TS5-6, and hydrogenolysis TS10-12 are essentially identical, meaning all three transition states play almost equal roles as TDTSs for the linear product. From this analysis, the experimental observation of positive orders in alkene and $\mathrm{H}_{2}$ and negative order in $\mathrm{CO}$ are reproduced by our DFT calculations. The absolute numbers for predicted turnover frequencies from this analysis suffer from inaccuracies related both to DFT and the application of simple transition state theory. That said, the energy span model provides a means through which to compare different means of generating the same small molecule or alternative branching pathways within one catalytic cycle. We find relative rates of $1.00,0.20$ and 0.56 for the $(S)$ branched, $(R)$-branched, and linear pathways respectively (see Table S7). This results in a predicted branched to linear selectivity of 68:32 (2.2) and er of 83:17, in excellent agreement with experimental values, 79:21 (3.8) and 93:7 er. The energy span model selectivities also match with those determined from the free energies of the hydride transfer transition states, TS5-6, alone, 83:27 (4.9) and 70:30 er, supporting the experimental findings that while hydride transfer is not solely turnover determining it plays the major role in determining the selectivity of the reaction products. $^{31}$

It is perhaps useful to comment here on the importance of dispersion corrections to our calculations. In the computational literature in general, as well as those directly concerning hydroformylation, ${ }^{24 c, 29 d, 29 e, 32}$ reports have found their incorporation, whether explicitly or through use of a functional with their inclusion, to be increasingly important. It is through their effect on NCIs that the impact is felt. ${ }^{33}$ In our studies, removal of the D3 dispersion corrections $^{34}$ resulted in the prediction that the linear and major branched transition states were isoenergetic, predicting a branched to linear ratio of $1: 1$. This inaccurate result held true even if dispersion corrections were included at the single point energy calculations but not during optimisation. Incorporation of dispersion corrections is clearly crucial for the correct prediction of regioselectivity and shows that the fine levels of regiocontrol displayed here are dictated by ligand-substrate non-bonding interactions, such as the $\mathrm{CH}-\pi$ interactions discussed above. Further, without dispersion corrections acyl dicarbonyl 9 species is not predicted to play a role as a resting state in the catalytic cycle at all (for the major $(S)$-branched pathway a resulting energy of $-2.2 \mathrm{kcal} \mathrm{mol}^{-1}$ without dispersion corrections instead of $-35.7 \mathrm{kcal} \mathrm{mol}^{-1}$ when dispersion is included) which would result in hydrido dicarbonyl 3 alone becoming the TDI (although in somewhat of a shallower potential energy well without dispersion corrections at $-10.9 \mathrm{kcal}$ $\mathrm{mol}^{-1}$ instead of $-17.7 \mathrm{kcal} \mathrm{mol}^{-1}$ ).

\section{CONCLUSIONS}

In order to build a better understanding of the origins of selectivity displayed during Rh/BOBPHOS catalysed asymmetric hydroformylation, combined experimental and computational studies have been undertaken on the model substrate allylbenzene. Kinetic profiling, spectroscopic study of catalytically competent intermediates, and deuterium labelling studies all conclude that hydrogenolysis plays no positive role in determining the high branched selectivity. Instead, selectivity is likely set during largely irreversible hydride transfer early in the catalytic cycle.

DFT calculations provide insights into these findings with excellent agreement observed between the relative energies of hydride transfer transition states and experimentally determined selectivities. The results are represented on a three-dimensional quadrant model accounting for the structural origins of regio- and enantioselectivities. An energy span and degree of TOF control analysis of the truncated catalytic potential energy surface for allylbenzene paralleled experimental results suggesting that, while selectivity is determined by hydride transfer, turnover is determined by both hydride transfer and hydrogenolysis for all product pathways. Calculating the selectivity required the addition of dispersion corrections during geometry optimisation.

The remarkable behaviour of Rh/BOBPHOS catalyst is now understood with a useful level of detail. Branched selective hydroformylation catalysts require a combination of leaving an open area for forming a branched Rh-alkyl, combined with the combination of preventing linear pathways from being productive, either by steric hindrance of by attractive interactions during an early stage in $\mathrm{C}-\mathrm{H}$ bond formation that forbids the formation of a branched $\mathrm{Rh}$ alkyl species. The goal of achieving high branched aldehyde selectivity in hydroformylation of unbiased alkenes, perhaps with even higher selectivity than with $\mathrm{Rh} / \mathrm{BOBPHOS}$, remains an important one in several sections of the chemicals industry and in organic synthesis.

\section{ASSOCIATED CONTENT}

\section{Supporting Information}

Experimental procedures, experimental and spectroscopic data, graphs related to kinetic studies, Cartesian coordinates, electronic energies, imaginary frequencies. This material is available free of charge via the Internet at http://pubs.acs.org.

\section{AUTHOR INFORMATION}

Corresponding Authors

*mb105@st-andrews.ac.uk

*mc28@st-andrews.ac.uk

ORCID

Paul Dingwall: 0000-0002-6961-7995 


\section{Notes}

The authors declare no competing financial interest. The research data underpinning this paper can be accessed at: http://dx.doi.org/10.17630/10.17630/0b84b1ad-176d-4185a6bb-48b6e02797fc

\section{ACKNOWLEDGEMENTS}

The authors thank Dr Chris Cobley (Dr Reddys UK) and Dr Gary Noonan (PhD with MLC 2010) for their important contributions in the development of Rh/BOBPOS catalyst. We thank the EPSRC for funding (EP/M003868/1). The technical support staff at the University of St Andrews are also gratefully acknowledged.

\section{REFERENCES}

(1) (a) Leeuwen, P. W. N. M. V.; Claver, C. Rhodium Catalyzed Hydroformylation; Kluwer Academic Publisher, Dordecht, 2000; (b) Franke, R.; Selent, D.; Börner, A. Chem. Rev. 2012, 112, 5675-5732; (c) Börner, A.; Franke, R. Hydroformylation. Fundamentals, Processes, and Applications in Organic Synthesis.; Wiley-VCH: Wiley-VCH Verlag $\mathrm{GmbH} \& \mathrm{Co} . \mathrm{KGaA}, 2016$.

(2) (a) Casey, C. P.; Whiteker, G. T.; Melville, M. G.; Petrovich, L. M.; Gavney, J. A.; Powell, D. R. J. Am. Chem. Soc. 1992, 114, 5535-5543; (b) Kranenburg, M.; van der Burgt, Y. E. M.; Kamer, P. C. J.; van Leeuwen, P. W. N. M.; Goubitz, K.; Fraanje, J. Organometallics 1995, 14, 30813089.

(3) Nozaki, K.; Nanno, T.; Takaya, H. J. Organomet. Chem. 1997, 527, 103-108.

(4) (a) Selent, D.; Franke, R.; Kubis, C.; Spannenberg, A.; Baumann, W.; Kreidler, B.; Börner, A.; Organometallics, 2011, 30, 4509-4514; (b) Güven, S.; Nieuwenhuizen, M. M. L.; Hamers, B.; Franke, R.; Priske, M.; Becker, M.; Vogt, D. ChemCatChem, 2014, 6, 603; (c) At $100^{\circ} \mathrm{C}$ and 20 bar pressure, the branched selectivity of allyl benzene hydroformylation drops to $1.7: 1(99 \%$ conversion in $1 \mathrm{~h})$

(5) Cobley, C. J.; Gardner, K.; Klosin, J.; Praquin, C.; Hill, C.; Whiteker, G. T.; Zanotti-Gerosa, A.; Petersen, J. L.; Abboud, K. A. J. Org. Chem. 2004, 69, 4031-4040.

(6) (a) Axtell, A. T.; Cobley, C. J.; Klosin, J.; Whiteker, G. T.; ZanottiGerosa, A.; Abboud, K. A. Angew. Chem. Int. Ed. 2005, 44, 5834-5838; (b) Fuentes, J. A.; Pittaway, R.; Clarke, M. L. Chem. Eur. J. 2015, 21 , 10645-10649.; Axtell, A. T.; Klosin, J.; Abboud, K. A. Organometallics 2006, 25, 5003-5009.

(7) (a) Clark, T. P.; Landis, C. R.; Freed, S. L.; Klosin, J.; Abboud, K. A. J. Am. Chem. Soc. 2005, 127, 5040-5042; (b) Watkins, A. L.; Hashiguchi, B. G.; Landis, C. R. Org. Lett. 2008, 10, 4553-4556; (c) McDonald, R. I.; Wong, G. W.; Neupane, R. P.; Stahl, S. S.; Landis, C. R. J. Am. Chem. Soc. 2010, 132, 14027-14029.

(8) (a) Zhang, X.; Coo, B.; Yu, S.; Zhang, X. Angew. Chem. Int. Ed. 2010 , 49, 4047;

(9). Dieguez, M.; Pamies, O.; Ruiz, A.; Castillon, S.; Claver, C. Chem. Commun. 2000, 1607-1608.

(10) (a) Wang, X.; Buchwald, S. L. J. Org. Chem. 2013, 78, 3429-3433; (b) Noonan, G. M.; Newton, D.; Cobley, C. J.; Surez, A.; Pizzano, A.; Clarke, M. L. Adv. Synth. Catal. 2010, 352, 1047-1054.

(11) (a) Besset, T.; Norman, D. W.; Reek, J. N. H. Adv. Synth. Catal. 2013, 355, 348. (b) Slagt, V. F.; Kamer, P. C. J.; van Leeuwen, P. W. N. M.; Reek, J. N. H. J. Am. Chem. Soc. 2004, 126, 1526-1536; (c) How, R. C.; Hembre, R.; Ponasik, J. A.; Tolleson, G. S; Clarke, M. L. Catal. Sci. Technol. 2016, 6, 118-124; (d) How, R. C.; Dingwall, P.; Hembre, R. T.; Ponasik, J. A.; Tolleson, G. S.; Clarke, M. L. Molecular Catalysis 2017, 434, 116-122 and ref's therein;

(12) Noonan, G. M.; Fuentes, J. A.; Cobley, C. J.; Clarke, M. L. Angew. Chem. Int. Ed. 2012, 51, 2477-2480.

(13) Noonan, G. M.; Cobley, C. J.; Mahoney, T.; Clarke, M. L. Chem. Commun. 2014, 50, 1475-1477.

(14) Pittaway, R.; Fuentes, J. A.; Clarke, M. L. Org. Lett. 2017, 19, 28452848.

(15) (a) Nozaki, K.; Sakai, N.; Nanno, T.; Higashijima, T.; Mano, S.; Horiuchi, T.; Takaya, H. J. Am. Chem. Soc. 1997, 119, 4413-4423; (b) Chikkali, S. H.; van der Vlugt, J. I.; Reek, J. N. H. Coord. Chem. Rev. 2014, 262, 1-15; (c) Robert, T.; Abiri, Z.; Wassenaar, J.; Sandee, A. J.; Romanski, S.; Neudörfl, J.-M.; Schmalz, H.-G.; Reek, J. N. H.
Organometallics 2010, 29, 478-483; (d) Fernández-Pérez, H.; BenetBuchholz, J.; Vidal-Ferran, A. Org. Lett. 2013, 15, 3634-3637; (e) Yan, Y.; Zhang, X. J. Am. Chem. Soc. 2006, 128, 7198-7202; (f) Deerenberg, S.; Kamer, P. C. J.; van Leeuwen, P. W. N. M. Organometallics 2000, 19, 2065-2072; (g) Rubio, M.; Suárez, A.; Álvarez, E.; Bianchini, C.; Oberhauser, W.; Peruzzini, M.; Pizzano, A. Organometallics 2007, 26, 6428-6436; (h) Nozaki, K.; Takaya, H.; Hiyama, T. Top. Catal. 1997, 4, 175; (i) Sakai, N.; Nozaki, K.; Takaya, H. J. Chem. Soc., Chem. Commun. 1994, 395-396; (j) Castillo Molina, D. A.; Casey, C. P.; Müller, Nozaki, K.; Jäkel, Organometallics, 2010, 29, 3362-3367.

(16) STREM catalogue number 15-0557.

(17) Steffen, W. L.; Palenik, G. J. Inorg. Chem. 1976, 15, 2432-2439.

(18) See Supporting Information

(19) Burés, J. Angew. Chem. Int. Ed. 2016, 55, 2028-2031.

(20) Blackmond, D. G. Angew. Chem. Int. Ed. 2005, 44, 4302-4320.

(21) van der Slot, S. C.; Kamer, P. C. J.; van Leeuwen, P. W. N. M.; Iggo, J. A.; Heaton, B. T. Organometallics 2001, 20, 430-441.

(22) (a) Watkins, A. L.; Landis, C. R. J. Am. Chem. Soc. 2010, 132, 10306-10317; (b) Nozaki, K.; Matsuo, T.; Shibahara, F.; Hiyama, T. Organometallics 2003, 22, 594-600.

(23) (a) Czauderna, C. F.; Cordes, D. B.; Slawin, A. M. Z.; Müller, C.; van der Vlugt, J. I.; Vogt, D.; Kamer, P. C. J. Eur. J. Inorg. Chem. 2014, 2014 1797-1810; (b) del Río, I.; Pàmies, O.; van Leeuwen, P. W. N. M.; Claver, C. J. Organomet. Chem. 2000, 608, 115-121; (c) van der Veen, L. A.; Boele, M. D. K.; Bregman, F. R.; Kamer, P. C. J.; van Leeuwen, P. W. N. M.; Goubitz, K.; Fraanje, J.; Schenk, H.; Bo, C. J. Am. Chem. Soc. 1998 120, 11616-11626; (d) Chikkali, S. H.; van der Vlugt, J. I.; Reek, J. N. H. Coord. Chem. Rev. 2014, 262, 1.

(24) (a) Brown, J. M.; Kent, A. G. J. Chem. Soc. Perk. T. 2 1987, 15971607; (b) Nelsen, E. R.; Landis, C. R. J. Am. Chem. Soc. 2013, 135, 96369639; (c) Gellrich, U.; Seiche, W.; Keller, M.; Breit, B. Angew. Chem. Int Ed. 2012, 51, 11033-11038.

(25) Brezny, A. C.; Landis, C. R. J. Am. Chem. Soc. 2017, 139, 2778-2785 (26) Evans, J.; Schwartz, J.; Urquhart, P. W. J. Organomet. Chem. 1974 81, C37-C39.

(27) Brookhart, M.; Green, M. L. H.; Parkin, G. PNAS 2007, 104, 6908 6914.

(28) (a) Contreras-Garcia, J.; Johnson, E. R.; Keinan, S.; Chaudret, R.; Piquemal, J. P.; Beratan, D. N.; Yang, W. T. J. Chem. Theor. Comput. 2011, 7, 625-632; (b) Johnson, E. R.; Keinan, S.; Mori-Sanchez, P.; Contreras-Garcia, J.; Cohen, A. J.; Yang, W. T. J. Am. Chem. Soc. 2010 $132,6498-6506$

(29) (a) Straker, R. N.; Peng, Q.; Mekareeya, A.; Paton, R. S.; Anderson, E. A. Nat. Commun. 2016, 7; (b) Knowles, R. R.; Jacobsen, E. N. PNAS 2010, 107, 20678-20685; (c) Armstrong, A.; Boto, R. A.; Dingwall, P.; Contreras-Garcia, J.; Harvey, M. J.; Mason, N. J.; Rzepa, H. S. Chem. Sci 2014, 5, 2057-2071; (d) Kumar, M.; Chaudhari, R. V.; Subramaniam, B.; Jackson, T. A. Organometallics 2014, 33, 4183-4191; (e) Kumar, M.; Chaudhari, R. V.; Subramaniam, B.; Jackson, T. A. Organometallics 2015, 34, 1062-1073; (f) Wagner, J. P.; Schreiner, P. R. Angew. Chem. Int. Ed. 2015, 54, 12274-12296; (g) Biedermann, F.; Schneider, H.-J. Chem. Rev. 2016, 116, 5216-5300; (h) Orlandi, M.; Coelho, J. A. S.; Hilton, M. J.; Toste, F. D.; Sigman, M. S. J. Am. Chem. Soc. 2017, 139, 6803-6806; (i) Neel, A. J.; Hilton, M. J.; Sigman, M. S.; Toste, F. D. Nature 2017, 543, 637-646.

(30) (a) Kozuch, S.; Shaik, S. Acc. Chem. Res. 2011, 44, 101-110; (b) Kozuch, S.; Martin, J. M. L. ACS Catalysis 2011, 1, 246-253.

(31) Gellrich, U.; Koslowski, T.; Breit, B. Catal. Sci. Technol. 2015, 5, 129-133.

(32) (a) Jacobs, I.; de Bruin, B.; Reek, J. N. H. ChemCatChem 2015, 7, 1708-1718; (b) Gellrich, U.; Himmel, D.; Meuwly, M.; Breit, B. Chem. Eur. J. 2013, 19, 16272-16281; (c) Carbó, J. J.; Maseras, F.; Bo, C.; van Leeuwen, P. W. N. M. J. Am. Chem. Soc. 2001, 123, 7630-7637; (d) Aguado-Ullate, S.; Guasch, L.; Urbano-Cuadrado, M.; Bo, C.; Carbo, J. J. Catal. Sci. Technol. 2012, 2, 1694-1704.

(33) Wheeler, S. E.; Seguin, T. J.; Guan, Y.; Doney, A. C. Acc. Chem. Res. 2016, 49, 1061-1069.

(34) Grimme, S.; Antony, J.; Ehrlich, S.; Krieg, H. J. Chem. Phys. 2010, 132. 


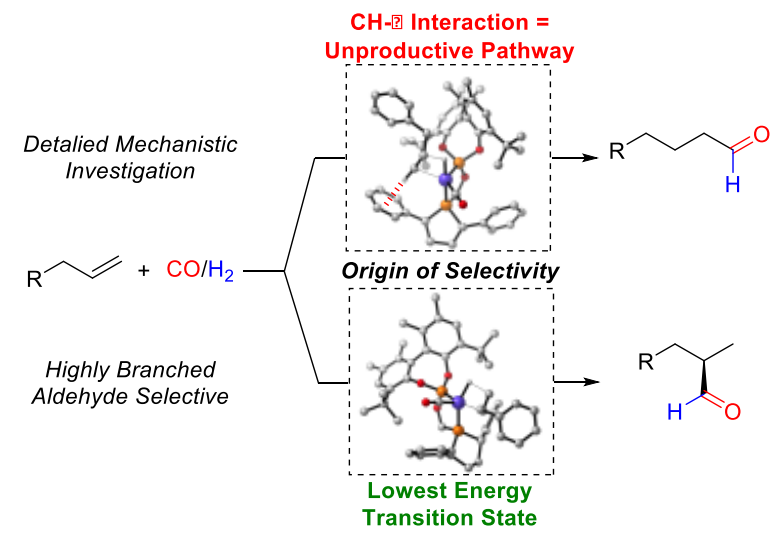

